\title{
The Role of Gender and Psychosocial Factors on Perceived Vulnerability to HIV/ AIDS Infection among Young and Middle Aged Adults in Benin City, Nigeria
}

\section{Taiwo Abigail Olubola}

Institute of Psychology, University of Wolverhampton, West midlands, United Kingdom

*Corresponding author: Taiwo Abigail Olubola, Faculty of Education, Health and Wellbeing, University of Wolverhampton, Mary Seacole Building, City Campus North, UKWV1 1AD, West Midlands. United Kingdom, Tel: 44(0)10902321346; E-maila.taiwo@wlv.ac.uk

Received: February 16, 2015, Accepted: April 10, 2015, Published: April 17, 2015

Copyright: @ 2015 Taiwo AO. This is an open-access article distributed under the terms of the Creative Commons Attribution License, which permits unrestricted use, distribution, and reproduction in any medium, provided the original author and source are credited.

\begin{abstract}
Objective: Nigeria's effort to curb the spiralling pandemic of HIV has yielded little result despite her reputation as the country with the second largest number of HIV infected persons in the world. Theories of preventive health behaviour posit that perceived vulnerability to health threats motivates self-protective behaviour. This study aimed to examine the predicting role of the psychosocial and gender factors in the perception of vulnerability to HIV infection.
\end{abstract}

Design: This survey study adopted a cross-sectional research design.

Method: Participants were young and middle aged adult-volunteers $(N=302$, male $=181$, female $=121$, mean age $=23.9$ years) drawn from four local Governments in Benin City of Nigeria. Participants responded to a standardized self-reported questionnaire consisting demographics, ambivalent sexism, gender stereotype, sexual assertiveness, health locus of control, and perceived vulnerability scales. Data analyses include descriptive, Pearson moment correlation, t-test, ANOVA and multiple regression analyses.

Result: Data showed that age, gender stereotype, hostile sexism, benevolent sexism, sexual assertiveness and health locus of control jointly accounted for $24.4 \%(p<0.001)$ of the variance observed in the participants' perception of their vulnerability to HIV infection. Independently, only gender stereotype and hostile sexism contributed significantly to the observed variance. Poor perception of vulnerability to HIV infection was significantly and positively related to hostile sexism, benevolent sexism, gender stereotype and higher external locus of control.

Recommendation: Attitude change programmes should be more gender sensitive and targeted to challenge sexist orientation, gender stereotypes and health belief system.

Keywords: Gender factors; Sexism; Psychosocial; Perceived vulnerability; HIV/AIDS

\section{Introduction/Background}

The Control of HIV/AIDS remains a major challenge globally, particularly in Nigeria and in other Sub-Saharan African countries $[1,2]$. Nigeria is recognized as the country with the second largest number of HIV-infected persons in the world $[3,4]$. The most recent sentinel report showed that the prevalence rate of HIV/AIDS infection in Nigeria stands at $4.1 \%$ (3.1 million) of the Nigerian population [5]. There are concerns that the rate may be under-reported as the government could give erroneous information due to management and logistic problems [6], but increase in the rate of new infections in some states has generated even greater concern [7-9]. The sentinel report also showed that the age-groups most vulnerable to HIV infection are the (15-39 years) young and middle aged adults [5,9]. Thus, the current study concentrated on the sample within this population.

Although HIV/AIDS is a biological entity that is responsive to medical interventions, the societal conditions that increase HIV risk and vulnerability need to be effectively addressed to stem its epidemic [1]. Previous studies have concentrated on factors that promote the actual risk and vulnerability to HIV/AIDS with less emphasis on people's perception of their vulnerability. However, studies have shown that people's perception can increase their HIV risk and vulnerability and also determine their HIV protection behaviour [10-14]. These studies follow the theories of planned behaviour $[15,16]$, protection motivation [17] and health belief model [18] which are based largely on people's beliefs about their own vulnerability to health risks. Essentially, if people do not perceive themselves as susceptible to a health threat, they are not likely to take preventive action and may thus be exposed to risk. Therefore, researchers across decades have identified people's perception of their vulnerability to HIV and AIDS as a significant area to study [10-23].

Despite the high prevalence of HIV infection, poor perceptions of people's vulnerability to HIV infection have been published in SubSahara Africa [1,24]. Thus, the people's poor perception of their vulnerability may render the medically oriented programmes such as free condom distribution, abstinence and avoidance of sharing sharp object campaigns ineffective.

Several individual characteristics and psychosocial factors could explain people's perception of their vulnerability to HIV/AID. In line with the reviewed literature, this current study aims to identify what types of association exist between gender, gender stereotypes, sexism, perceived sexual assertiveness, health locus of control, age and 
perceived vulnerability to HIV infection among the middle aged and young adults in Benin City of Nigeria. The study further examined the extent to which these factors jointly and individually predict participants' perceived vulnerability to HIV infection.

Abounding literature identified gender factors (including gender, sexism, and gender stereotypes) as significant drivers of HIV infection in HIV/AIDS prevalent areas $[13,25,26]$. Gender, as a cultural symbolization of sexual difference has had a profound mark on human existence and has been linked with increased vulnerability to HIV infection [1,27-29]. Specifically, gender inequality has been implicated for increased risk and vulnerability to HIV infection as well as sexual risk behaviour [26-31]. Researchers noted that gender inequality is often borne out of gender stereotypes and sexist orientation [32,33]. Liguori \& Lamas [34] noted that sexism is derived from a gender logic that is deadly in the context of AIDS. One concept introduced by Glick and Fiske [35] and has been found to be capable of exposing gender discriminations that are at the root of gender inequality is Ambivalent Sexism (AS) $[32,35,36]$.

Although, Ambivalent sexism has been widely examined as it relates to some sexual relationship issues such as harassment and partner abuse [35,37-42], it has not been examined in relation to perception of vulnerability to HIV infection. It is an ideology that identifies an antagonistic or chivalrous attitude toward women in which they are either viewed as trying to control men through feminist ideology or sexual seduction (hostile sexism), or casts women as weak creatures in need of men's protection (Benevolent sexism). Ambivalent sexism tends to capture these two dimensions ideology, yet, ideologies that people hold have been reported to be significant in the way they perceive issues. For example, ideologies in different forms have been found to shape intergroup perceptions among the Latinos and blacks in America as well as the ethnic identity of children. Elite ideology has also been found to underlie risk perception in nuclear energy policy while superficial or non-superficial ideology influence perceptions of credibility and construct societal norms. Ambivalent sexism as a form of gender inequality ideologies, and lack of empowerment of women and girls has been identified as part of the societal factors that affect HIV risks and vulnerability [1,28]. WHO [2] added that the same gender factors that expose women and girls to the infection of HIV and AIDS can also strengthen the vulnerability of men and boys to HIV infection. While direct links of these gender factors to actual HIV risks and vulnerability have been observed, the relationship between these factors and perception of vulnerability has not been well researched.

Sexual assertiveness is another factor that has been implicated in literature in relation to the study of HIV/AIDs infection. For example, sexual assertiveness was considered to be an important factor for effective HIV/AIDS prevention. This refers to the ability and/or confidence to initiate, sustain or dislocate a sensuous conversation without blushing. But while Vaughn et al., [2002] felt that this understanding is critical to developing effective interventions to promote sexual health and reduce sexual risk-taking and vulnerability to HIV infection, others have blamed sexual assertiveness for the breakdown of virginity culture as a normative idea for adolescent girls in Nigeria [43]. Yet, some other studies showed that HIV/AIDS prevention programmes that incorporate sexual assertiveness (e.g. say no to unprotected sex) are quite effective [43-45]. As there is no consensus among authors on the role of sexual assertiveness in HIV/ AIDS literature, the current study aims to explore its role in the participants' perception of their vulnerability to HIVAIDS.
In addition to this, variations in individuals' belief about the control of their health has gained substantial investigation in behavioural health related literature [46-50]. The concept of 'health locus of control' was introduced to describe one's belief about the control of one's own health and this is supported by the 'theory of attribution' $[49,50]$. According to attribution theory people ascribe the control of their health to either internal or external factors. This form of attribution has been found to influence health-related behaviour including HIV risks and number of sexual partners in studies that focused on people's sexual networking $[11,26,51,52]$. Lower external locus of control has also significantly predicted positive condom use attitude among African-American adolescents $[47,53]$. It may be that the participants' locus of control will also explain the perception of their vulnerability.

Demographic factors such as age and marital status in relation to perception of vulnerability to HIV infection have also been well researched $[7,11,22,24,27]$. Some studies from Africa showed that young people often perceive their risk of HIV infection to be low even if they engage in HIV/AIDS risk behaviour, live in areas with high HIV prevalence rates, or are knowledgeable about HIV/AIDS [13,27, $29,31,54,55]$. Young people (ages 15-24) were identified as the most vulnerable to HIV infection [1] and $60 \%$ of all new infections were among young people in sub-Saharan Africa [26]. Kimbobo et al's [11] study revealed that young people with broken marriages are much more vulnerable to high risk sexual networking than other categories of adolescents [51].

Based on the implication of the above factors as capable of influencing perceived vulnerability to HIV/AIDs in the reviewed literature, the following hypotheses were tested in the current study:

1. Unmarried sexually active condom non-users will significantly perceive their vulnerability poorly than unmarried sexually active condom users and married condom user or non-users.

2. Gender, gender stereotype, hostile sexism, benevolent sexism, health locus of control, perceived sexual assertiveness and age will conjointly contribute significantly to the explanation of the variance observed on participants' perceived vulnerability to HIV infection.

3. There will be a significant independent contribution of gender, gender stereotype, hostile sexism, benevolent sexism, health locus of control, perceived sexual assertiveness and age to the explanation of the variance observed on participants' perceived vulnerability to HIV infection.

4. A significant inter-correlation of perceived vulnerability, ambivalent sexism, hostile sexism, benevolent sexism, gender stereotype and sexual assertiveness will be observed among the participants.

\section{Method}

\section{Design}

This study adopted a cross-sectional survey design. The main independent variables of interest are gender, gender stereotype, condom use status, ambivalent sexism (which include hostile and benevolent sexism), health locus of control, age and perceived sexual assertiveness. Perceived vulnerability to HIV/AIDs infection serves as the outcome variable in this study. Although, not many of the participants were married, it was necessary to match them on their 
marital status as this factor was implicated for perceived vulnerability in literature.

\section{Participants}

Young and middle aged volunteers $(\mathrm{N}=302$; mean age $=23.9$ years, age range $=18$-35) drawn from four local Governments (Oredo, Iguneben, Ovia South West and Ovia South East) in Benin City of Nigeria through opportunistic sampling participated in this study. $60 \%$ of the participants were between age 18-24 years (mean age $=$ 21.8 ) while the rest $40 \%$ were between age 25 -35years (mean age $=27$ years). In all, 181 males and 121 females participated in the study. Significant characteristics of the participants are highlighted on Tables $1 \& 2$ in the results section.

\section{Procedure}

Following the theory of preventive health behaviour and health belief model, Four Focus Group Discussions (FGD, N=28, age range = 17-35) and 10 In-depth Interviews (IDIs) were first conducted at Benin City. The aim is to elicit free flow responses about the people's perception, ideas and beliefs relating to HIV as well as questions about gender beliefs in relation to HIV infection. The responses were transcribed, out of which items for perceived vulnerability and gender stereotype questionnaires were generated. These two questionnaires were combined with the other existing standardised instruments and pilot-tested on a sample of 30 youths to ensure readability, ease of understanding and reasonable completion time. Permission to conduct the study was first obtained from each of the Local Government councils through the Department of community and Primary health. The community health team gave their support and advised on when to distribute the questionnaires. Questionnaires were distributed in the evenings when participants were relaxing and recreating with football and other games. Those in view were approached and informed about the goal of the study after which verbal consent to participate was obtained from them. Only those who gave their consent to participate in the study were given questionnaires to complete. The only condition to participate was being a young or middle aged adult (18-45 years old). 500 questionnaires were distributed out of which 350 were returned, but only 302 (i.e. $86.3 \%$ ) had no missing data and these were the only ones included in the analyses.

\section{Measures}

A questionnaire booklet containing scales and demographic factors was administered in English language only to the participants. The need for translation to indigenous language of the participants did not arise at any point of the data collection. The predictor variables were the subscales of ambivalent sexism (that is, benevolent and hostile sexism), gender stereotype, gender in terms of male and female, Perceived Sexual Assertiveness (PSA), Health Locus of Control (HLC) and age. The dependent variable was the perceived vulnerability to HIV infection (PV).

Demographics: Participants indicated their socio-demographic factors such as age, gender, marital and sexuality status (including number of partners, sexual networking and use of protective materials, e. g. condoms) at this section.

Ambivalent Sexism: The 22 items Ambivalent Sexism Inventory (ASI) developed and standardised by Glick et al. [33] was used to measure this construct. It is a paper and pencil test and has two ideological subscales: hostile sexism (HS) (measuring antagonistic prejudice) and benevolent sexism (BS) (measuring chivalrous attitude sexism). The response format ranged from strongly disagree (score $=1$ ) to strongly agreed $($ score $=5)$. Sample items for hostile sexism include phrases like "Most women fail to appreciate all that men do for them"; "Women seek to gain power by getting control over men"; "Most women interpret innocent remarks or acts as being sexist." Sample items for benevolent sexism are "Women should be cherished and protected by men"; "Many women have a quality of purity that few men possess"; "A good woman ought to be set on a pedestal by her man". A hostile sexism score was computed for each participant by computing the mean of each participant's responses to the 11 items composing this scale. A benevolent sexism score was computed in an analogous manner. An overall ASI score was computed by taking an average of all the items on both the hostile and benevolent scale for each participant. Cronbach's alpha was 0.71 and this is consistent with reliability report from prior research on the ASI $[33,56]$.

Gender Stereotypes: This construct was measured using the nineitem self-developed scale, designed to identify gender based ignorance and stereotypes among the participants. The 9- items for the scale were originally part of the 16 statements generated from in-depth interviews conducted among twenty respondents from same study area as the current study in Benin, on their thought about the use of HIV preventative facilities available. Response format was in Likert scaling, ranging from strongly disagree $=1$ to strongly agree $=5$. Sample items include "Females who insist on condom use during sexual intercourse are promiscuous,", "Female HIV infected persons should be more strongly stigmatized and exposed than the male", "Females cannot decide on contraceptive usage, only males can," "a woman belongs to her husband, but the husband belongs to all". The extracted items were given to three psychology experts in the field of gender and reproductive health to rate the extent to which each item measures the construct of gender stereotype and ignorance on a 10 point scale. Only 16 of the items received $100 \%$ agreement of the raters as measuring the construct. These 16 items were then then subjected to item total statistics to establish its reliability. Only 9 items with the corrected item total correlation ranging from $0.34-0.45$ were retained for data collection. A Cronbach co-efficient alpha of 0.70 was obtained for the scale.

Perceived Sexual Assertiveness: A perceived sexual assertiveness scale designed by the Counselling Centre, State University of New York at Buffalo [57] and used in a study previously reviewed above was adopted in this study. This scale consisted of 13 items starting with the phrase "I have the right to:" Participants indicated whether they felt that they never, sometimes or always have the right to engage in each of the behaviours and were expected to express whether they "never" (scored 0), "sometimes" (scored 1) or "always" (scored 2) assert themselves on the issue of sexual behaviour. Sample Items included; "tell my partner I won't have intercourse without birth control," "tell my partner I want to make love differently," "tell my partner I want to be hugged or cuddled without sex." Higher scores indicate a high perceived level of assertiveness. The scale yielded a Cronbach coefficient alpha of 0.78 for the present study.

Health Locus of Control: This construct was measured using the 11 items health locus of control scale (5 items measured internal locus of control and 6 items measured external locus of control) [49]. All negatively worded items indicated external control while positively worded items indicated internal locus of control. It is a five point Likert scale ranging from strongly agree (score 5) to strongly disagree 
Page 4 of 8

(score 1). Those scoring above the mean are labelled "health-externals" and those scoring below the mean are labelled "health internals." External refers to the belief that one's outcome is under the control of powerful others (i.e., doctors) or is determined by fate, luck or chance. Internal refers to the belief that one's outcome is directly the result of one's behaviour. The items included phrases like: "No matter what I do, if I am going to get sick I will get sick." Whenever I get sick, it is because of something I have done or not done," "People's ill-health results from their own carelessness", "People who never get sick are just plain lucky". Cronbach coefficient alpha was 0.71 and was similar to the authors' own reported alpha [49].

Perceived vulnerability: The participants' perceived vulnerability to HIV infection was measured using the empirically and theoretically based 11-items self-developed scale (PVS). The scale follows the social cognitive model of health behaviour (the health belief model) which assumes that people's beliefs and attitudes serve as proximal determinants of their behaviour. Items for the scale were extracted from data generated through Focus Group Discussions (FGD) and Indepth Interviews (IDI). Only 11 items out of the extracted 20 statements met the psychometric criteria of 0.4 for their corrected item total correlation and were retained for data collection. Higher scores on the scale indicate poor perception of vulnerability while lower scores indicate better perception of vulnerability. It is on a 5-point Likert scale ranging from Strongly Agree (Score-5) to Strongly Disagree (Score-1). The scale started with the phrase "I am not vulnerable to HIV infection"; "even if I do not protect myself during sex," " if I am a female because females do not need to protect themselves during sex", "even if I share my personal sharp objects such as blade, brush and other objects in common with members of my family," "even if I have multiple sex partners, it is just fun," "even if I don't use condom during sexual intercourse with my sex partners." The scale yielded a Cronbach's alpha of 0.71 when subjected to reliability exercise.

Analyses: All analyses of the data collected were carried out with the IBM SPSS statistics 20. A p value of .05 was adopted for all statistical tests. The descriptive statistics were adopted to explore the relationship of the socio-demographic characteristics with the main variables of interest in the study and to establish the participants' sexual networking patterns. A $2 \times 3$ ANOVA was adopted to test hypothesis 1 , multiple regression (enter method) for hypothesis 2 and 3 , and inter-correlation (Pearson $\mathrm{r}$ ) analysis for hypothesis 4 .

\section{Result}

This section presents the descriptive analysis results (tables $1 \& 2$ ) and the results of the hypotheses tested (tables 3-6).

\begin{tabular}{|l|l|l|l|l|l|l|l|}
\hline \multicolumn{3}{|l|}{ Gender } & & \multicolumn{2}{|l|}{} & \\
\hline A & Male & Female & Total & \multicolumn{2}{|l|}{$\mathrm{t}$ - test result } \\
\hline Variables & Mean & Mean & Mean & T & Df & P \\
\hline $\begin{array}{l}\text { Perceived } \\
\text { Vulnerability }\end{array}$ & $31.5(7.3)$ & $28.2(6.2)$ & $30.2(7.1)$ & 4.0 & 300 & 0.001 \\
\hline Ambivalent Sexism & $82.5(9.1)$ & $78.5(9.3)$ & $80.9(9.4)$ & 3.7 & 300 & 0.001 \\
\hline Hostile sexism & $41.2(4.9)$ & $38.6(5.2)$ & $40.1(5.2)$ & 4.4 & 300 & 0.001 \\
\hline Benevolent sexism & $41.3(5.4)$ & $39.9(5.1)$ & $40.8(5.3)$ & 2.3 & 300 & 0.022 \\
\hline
\end{tabular}

\begin{tabular}{|l|l|l|l|l|l|l|}
\hline $\begin{array}{l}\text { Sexual } \\
\text { assertiveness }\end{array}$ & $34.6(6.3)$ & $36.0(6.4)$ & $35.1(6.3)$ & 1.9 & 300 & 0.061 \\
\hline Gender stereotypes & $32.3(6.3)$ & $28.0(7.3)$ & $30.6(7.1)$ & 5.5 & 300 & 0.001 \\
\hline $\begin{array}{l}\text { Health Locus of } \\
\text { control }\end{array}$ & $39.8(5.5)$ & $38.3(5.4)$ & $39.3(5.5)$ & 2.1 & 300 & 0.033 \\
\hline
\end{tabular}

Table 1: Demographics - the Comparisons of the participants' scores by their gender on the standardised scales. Note: standard deviations are in parentheses on the table

\section{Descriptive statistics}

The comparisons of the mean scores for the male and female participants $(\mathrm{N}=302)$ on the standardised scales used in this study were analysed and presented on table 1 below.

\begin{tabular}{|c|c|c|}
\hline Question & Frequency & Percentage \\
\hline \multicolumn{3}{|l|}{ Have you ever had sex? } \\
\hline No response & 33 & 11 \\
\hline Never had sex & 164 & 54 \\
\hline Have had sex & 105 & 35 \\
\hline \multicolumn{3}{|c|}{ How frequent do you have sex } \\
\hline No response & 33 & 11 \\
\hline Never & 164 & 54 \\
\hline Once a month & 28 & 9 \\
\hline 2-4 times a month & 16 & 6 \\
\hline Weekly sexual contact & 61 & 20 \\
\hline \multicolumn{3}{|l|}{ How many sex partners } \\
\hline No response & 20 & 7 \\
\hline None & 90 & 30 \\
\hline Only one Partner & 131 & 43 \\
\hline 2 Partners only & 38 & 13 \\
\hline 3 or more partners & 23 & 7 \\
\hline \multicolumn{3}{|c|}{$\begin{array}{l}\text { Do you protect yourself (e.g. with } \\
\text { condom) during sex? }\end{array}$} \\
\hline No response & 16 & 5.3 \\
\hline No & 256 & 84.8 \\
\hline Yes & 30 & 9.9 \\
\hline \multicolumn{3}{|l|}{ Marital status } \\
\hline No response & 1 & 0.3 \\
\hline Singles & 280 & 92.7 \\
\hline Married & 21 & 7.0 \\
\hline
\end{tabular}

Table 2: Demograhphics - sexual networking characteristics among the participants 
Page 5 of 8

The result showed that male and female differ significantly on all the measures with the effect size ranging from 1.9-5.5 ( $\mathrm{p}<0.05)$. In total, $166(55 \%)$ of the participants scored below the mean on perceived vulnerability scale, while 136 (45\%) scored higher than the mean.

Table 2 showed the sexual networking characteristics of the participants. $85 \%$ indicated that they were not protecting themselves during sex while $20 \%$ reported that they have more than one partner, yet most of the participants (93\%) were still single.

\section{Hypotheses testing}

The first hypothesis proposed that the unmarried sexually active condom non-users will significantly perceive their vulnerability more poorly than unmarried sexually active condom user and married condom user or non-user. A $2 \times 3$ Analysis of Variance (ANOVA) yielded the result presented on Table 3 below

\begin{tabular}{|l|l|l|l|l|l|}
\hline Source & SS & Df & Ms & F & P \\
\hline Condom use (C) & 666.80 & 2 & 333.40 & 6.95 & 0.001 \\
\hline Marital status (MS) & 12.57 & 1 & 12.57 & 0.26 & 0.609 \\
\hline C*MS & 29.38 & 2 & 14.69 & 0.31 & 0.737 \\
\hline Error & 14259.26 & 296 & 48.17 & & \\
\hline
\end{tabular}

Table 3: Summary of the $2 \times 3$ ANOVA examining the interaction of marital status and condom use on Perceived Vulnerability scores

Table 3 showed that marital status did not interact significantly with condom use but there was significant difference on the perceived vulnerability scores of participants when grouped by their condom use report $(\mathrm{F}(2,296)=16.95, \mathrm{p}<0.001)$. This was subjected to means score comparison analysis and result was presented as table 4 .

\begin{tabular}{|l|l|l|l|l|l|l|}
\hline Groups & 1 & 2 & 3 & $\mathrm{~N}$ & $\begin{array}{l}\text { Perceived } \\
\text { vulnerability } \\
\text { mean score }\end{array}$ & SD \\
\hline 1 & - & -99 & $-5.82^{*}$ & 16 & 28.75 & 7.05 \\
\hline 2 & & - & $-4.83^{*}$ & 256 & 39.74 & 6.82 \\
\hline 3 & & & - & 30 & 34.57 & 7.67 \\
\hline Total & & & & 302 & 30.17 & 7.05 \\
\hline
\end{tabular}

Table 4: Scheffe comparison for the influence of condom use on perceived vulnerability (PV) score. Key ${ }^{\star} \mathrm{p}<0.05$. Group $1=$ No response; $2=$ Non condom users; $3=$ Condom users

Result of the Schefe comparison showed that the condom users scored significantly higher ( mean score $=34.6 ; \mathrm{p}<0.05$ ) on perceived vulnerability than the non-condom users and no response groups, implying that they significantly reported poorest perception of their vulnerability than other groups (table 4).

The second hypothesis proposed that gender stereotype, hostile sexism, benevolent sexism, health locus of control, perceived sexual assertiveness and age will significantly and jointly predict participants' perceived vulnerability to HIV infection. Result suggested that hypothesis two is confirmed. Table 5 below showed that all the variables in the model significantly predicted and explained a significant proportion of variance in perceived vulnerability of the participants $(\mathrm{R}$ square $=0.244, \mathrm{~F}(6,295),=15.890, \mathrm{p}<0.001)$.

\begin{tabular}{|l|l|l|l|l|}
\hline Predictor variable & B & SE(B) & $\beta$ & Sig (P) \\
\hline Age & 0.24 & 0.11 & 0.05 & 0.637 \\
\hline Gender Stereotype & 0.38 & 0.06 & 0.38 & 0.001 \\
\hline Sexual Assertiveness & 0.09 & 0.06 & 0.10 & 0.088 \\
\hline Health Locus of Control & 0.05 & 0.08 & 0.06 & 0.436 \\
\hline Hostile Sexism & 0.19 & 0.09 & 0.26 & 0.004 \\
\hline Benevolent Sexism & 0.06 & 0.09 & 0.08 & 0.357 \\
\hline
\end{tabular}

Table 5: Summary of regression analysis showing the predictors of perceived vulnerability to HIV infection among the participants. Note: $\mathrm{R} 2=0.244$

Although, table 5 indicated that all the variables jointly accounted for $24.4 \%$ of the variance observed in the participants' perception of their vulnerability to HIV infection, only two variables (gender stereotypes and hostile sexism) significantly independently contributed to this variance $(\beta=0.384 ; \mathrm{t}(295)=6.6 ; \mathrm{p}<0.05$ and $\beta=0.190 ; \mathrm{t}(295)=2.871 ; \mathrm{p}<0.004$ respectively). Therefore, the third hypothesis was partially confirmed. The collinearity diagnosis excluded ambivalent sexism for low tolerance (0.02) and VIF of 15.

\begin{tabular}{|l|l|l|l|l|l|l|}
\hline Measures & $\begin{array}{l}\text { Hostile } \\
\text { Sexism }\end{array}$ & $\begin{array}{c}\text { Benevolent } \\
\text { sexism }\end{array}$ & $\begin{array}{l}\text { Health } \\
\text { Locus } \\
\text { of } \\
\text { control }\end{array}$ & $\begin{array}{c}\text { Gender } \\
\text { Stereotypes }\end{array}$ & $\begin{array}{l}\text { Perceived } \\
\text { vulnerability }\end{array}$ & $\begin{array}{l}\text { Ambivalent } \\
\text { Sexism }\end{array}$ \\
\hline $\begin{array}{l}\text { Sexual } \\
\text { assertiveness }\end{array}$ & 0.03 & 0.09 & $0.26^{* *}$ & 0.04 & $0.12^{*}$ & 0.07 \\
\hline $\begin{array}{l}\text { Hostile } \\
\text { Sexism }\end{array}$ & - & $0.61^{* *}$ & $0.39^{* *}$ & $0.35^{* *}$ & $0.31^{* *}$ & $0.89^{* *}$ \\
\hline $\begin{array}{l}\text { Benevolent } \\
\text { Sexism }\end{array}$ & - & $0.38^{* *}$ & $0.33^{* *}$ & $0.71^{* *}$ & $0.90^{* *}$ \\
\hline $\begin{array}{l}\text { Health } \\
\text { Locus } \\
\text { Control }\end{array}$ & & & - & $0.45^{* *}$ & $0.29^{* *}$ & $0.43^{* *}$ \\
\hline $\begin{array}{l}\text { Gender } \\
\text { Stereotype }\end{array}$ & & & & - & $0.45^{* *}$ & $0.38^{* *}$ \\
\hline $\begin{array}{l}\text { Perceived } \\
\text { Vulnerability }\end{array}$ & & & & - & $0.29^{* *}$ \\
\hline
\end{tabular}

Table 6: Summary of the Pearson correlations between hostile sexism, benevolent sexism, gender stereotype, sexual assertiveness, health locus of control and perceived vulnerability to HIV/AIDS infection. Key: ${ }^{\star}=\mathrm{P}<0.05 ;{ }^{* *}=\mathrm{P}<0.001$.

Hypothesis four proposed that sexual assertiveness, hostile sexism, benevolent sexism, health locus of control, gender stereotype, ambivalent sexism and perceived vulnerability to HIV infection will significantly inter-correlate. Pearson correlation showed how these factors inter-correlated with each other on Table 6 below. 
All the factors were significantly inter-correlated except the sexual assertiveness which had no significant relationship with gender stereotype and sexism (i.e. benevolent, hostile and ambivalent) (Table 6). Hypothesis 4 is therefore partially supported. The result on Table 6 also showed sexual assertiveness, gender stereotype, health locus of control, as well as ambivalent sexism, hostile sexism and benevolent sexism as significant (positive) correlates of the perceived vulnerability to HIV infection among the participants. The result further revealed that the relationship of sexisms (ambivalent, hostile and benevolent), gender stereotype and sexual assertiveness with health locus of control was significant and positive (Table 6).

\section{Discussion, Conclusion and Implication of Findings}

This study was conducted to investigate the role of gender factors (gender, gender stereotype, sexism) and psychosocial factors (sexual assertiveness and health locus of control) in the prediction of perceived vulnerability to HIV infection among the young and middle aged adults. These adult volunteers were recruited from four local governments in Benin City of Nigeria. Based on the theory of preventative behaviour, the study hypothesised that people's perception of their vulnerability to HIV infection could be an important factor in determining or predicting their self-protective behaviour and their involvement in HIV prevention programmes and activities [10,14,15,17].

The descriptive statistics (Table 1) showed that male participants significantly scored higher on perceived vulnerability than females, implying that they had a poorer perception of their vulnerability to HIV infection than the female participants. This finding has gained support from literature [34]. This notwithstanding, findings examining gender differences in the perceived vulnerability have been mixed. A study by Mwamwanda [26] and University of California reported contrary findings in which females reported poorer perceived vulnerability than males. Table 2 showed that about $64 \%$ of participants have had sex with one or more partners, thus supporting the earlier reports that these young and middle aged adults were the more vulnerable group as they actively network sexually [51,58]. This form of behaviour has been identified as key driver for the spread of new HIV infections in some countries [51]. Despite the popularity of condoms, a high percentage (85\%) of the participants reported that they were not using any protective shield during sex, which may be an implication that these adults are either minimizing their level of vulnerability, or perceived their vulnerability poorly. It is interesting to realise that even those who confess condom use significantly perceived their vulnerability to HIV infection more poorly compared to others (tables 3 and 4). Since vulnerability to HIV infection is not only through sex (which makes condom use relevant), other conditions which expose one to the risk of HIV infection might actually have been poorly perceived among the condom users. Past findings, which showed that when people's perception of their vulnerability is poor, their HIV protective or preventive behaviour will also be poor $[10,14,15,17,30]$ might be used to explain this finding.

As findings from this study also (Table 5) showed that gender factors (gender stereotype, hostile sexism and benevolent sexism) sexual assertiveness, health locus of control, and age jointly accounted for $22.9 \%(p<0.001)$ of the observed variance in the participant's perceived vulnerability to HIV infection, it has reinforced previous findings which emphasised the significance of gender factors in peoples' perception of their vulnerability to HIV infection $[1,25,28-31]$. The result further shows only gender stereotype and hostile sexism as significant contributors to the observed variance (Table 5), thus presenting gender stereotypes and sexism as promoters of poor perception of vulnerability to HIV/AIDS in among the study participants. It might be that the socialisation norm is implicated here where women (and girls) are socialised not to make informed decisions concerning their reproductive health or related matters without their partners approval otherwise they run the risk of being labelled "infidel" or "rebellious" [55,59].

The significant inter-correlation of the variables examined in this study (table 6) made it complex to reject any of the factors on the ground that it has not significantly predicted the perceived vulnerability to HIV infection. This observed significant intercorrelation of the variables might explain why some of these factors have not predicted perceived vulnerability to HIV infection independently. The positive relationship of health locus of control and other variables (Table 6) implied that individuals who believe that their health conditions are not under their personal control, but due to luck or influential others (higher external locus of control) may be more likely to perceive themselves as more sexually assertive, possess more sexist orientations and perceive their vulnerability to HIV infection more poorly (Table 6). Association of higher external locus of control with poor perception of vulnerability to HIV infection lend support to previous studies which reported a significant association between internal health locus of control and more positive attitudes toward precautionary sexual behavior [46,47].

The fact that hostile sexism and benevolent sexism was significantly related (Table 6) lends support to past findings $[35,36]$. The result that showed hostile sexism and benevolent sexism as correlates of perceived vulnerability among participants (Table 6) reinforced the observation of Liguori et al [34] \& Albarracin et al. [28]. They stated that sexism of any type should be earnestly confronted because of its implication for preventing further spread of AIDS. Moreover, ambivalent sexism is a measure of gender inequality and the participants' overall average score of 80.9 appears relatively higher than the average scores of other non-African countries studied $[35,56]$. This result has once more confirmed that gender inequality still prevails in the Nigerian society and, as well, relates to people's perception of their vulnerability to HIV infection (Tables 5 \& 6). Rao [60] noted that the imbalance of power between women and men in gender relations curtails women's sexual autonomy and expands male sexual freedom, thereby increasing women's and men's risk and vulnerability to HIV infection. This finding provides empirical support for the long time observation that gender factors are significant in the spread of HIV infection $[2,12,24]$. It has also reemphasised the need for a gender sensitive intervention to curtail the spread of HIV infection. The need to target the imbalance of power between women and men in gender relations therefore appears to be very critical in the design of programmes to reduce men and women's risk and vulnerability to HIV infection.

\section{Limitation of the study}

Although all the questionnaires adopted for data collection in this study were standardised and psychometrically robust, information obtained were mainly self-reported which could be susceptible to subjective bias. Also, the study adopted a cross-sectional survey design, meaning that the study has been carried out at one time point and so could not guarantee that the same result will be obtained if the study is replicated. The sample size may not be representative of the whole young and middle aged adults in Nigeria. More so, the minimum age 
in this study is 18 as the study concentrated on young and middle aged adult. Previous research showed that older adolescent and young adults (ages 15-24) were the most vulnerable to HIV infection in Nigeria. A study designed for wider coverage of different parts in Nigeria is therefore suggested. The author has not inferred causality from the findings. Hence, caution must be exercised in interpreting the finding of this study.

\section{Conclusion and Recommendation}

Findings from this study showed that gender stereotype and hostile sexism were independently related to perceived vulnerability to HIV infection. Also both types of sexism (hostile and benevolent), gender stereotypes, sexual assertiveness and Health Locus of control were significant predictors of perceived vulnerability to HIV infection among the young and middle aged adults in Benin city of Nigeria. The result indicates that research into causes of widespread transmission of HIV infection should encompass gender and psychosocial factors and these factors should be addressed adequately. More inclusive study to examine the influence of gender factors as well as the design of gender sensitive prevention programmes is required across Nigeria. These become imperative now that it is globally recognized that Nigeria is among the significant five nations in the world that requires urgent attention to stem the next global wave of HIV/AIDS [4]. It is suggested that the variables that have not significantly predicted but related significantly with perceived vulnerability to HIV infection in this study should not be overlooked while packaging attitude change programmes. Although, it is laudable to assume that if significant predictors are addressed, the other related factors will also be addressed, but the situation can be more complex. It is therefore suggested that each individual's psychological needs and belief system should be recognized and be given adequate attention when packaging HIV/AIDS awareness and prevention programmes for a more positive result. For example, individuals with higher external locus of control may quickly grasp information about HIV as it comes from experts or influential figures such as Doctors and other recognised professionals, whereas, those with higher internal locus of control might benefit more from testimonies of individuals who are already infected as a result of what they have done or not done in the past.

\section{References}

1. Joint United Nations programmes on HIV/AIDS (UNAIDS) (2008) Reports on the Global AIDS Epidemic.

2. World Health Organisation (2003) Integrating Gender into HIV/AIDS programmes. Department Of Gender And Women's Health.

3. Joseph R (2010) Nigeria'sP HIV/AIDS pandemic: Time for Bolder action. A global economy and development event. Brooking Institution, Washington DC.

4. United States National Intelligence Council (2002) The next wave of HIV/AIDS: Nigeria, Ethiopia, Russia, India, and China.

5. Federal Ministry of Health (2010) National HIV Sero-Prevalence Sentinel Survey among Pregnant Women Attending Antenatal Clinics in Nigeria: Technical Report, National AID/STDs Control Programme.

6. Ekpo IA (1994) Coping with AIDS situation in Southern Africa. National Prevention Policies and Programme Responses. World Bank Economic Development Institute, Washington DC

7. Odutolu O, Ahonsi BA, Gboun M, Jolayemi OM (2006) The national response to HIV/AIDS. In: Aids in Nigeria: A Nation on the threshold. Adeyi O, Kanki PJ, Odutola O, Idoko JA (Eds.), Harvard Centre for Population and Development Studies, Harvard.
8. Oyefara JL (2013) Sociology of HIV/AIDS Pandemic in Nigeria. Developing country studies, 3: 117-122.

9. Abah RC (2014) The demographic implications of the HIV prevalence trend in Nigeria. Journal of Public Health in Africa 5: 19-22.

10. Teague SM (2009) Perceptions of vulnerability to HIV/AIDS: a comparison of two college cohorts, 1990 and 2005. AIDS Educ Prev 21: 526-537.

11. Kibombo R, Neema S, Ahmed FH (2007) Perceptions of risk to HIV infection among adolescents in Uganda: are they related to sexual behaviour? Afr J Reprod Health 11: 168-181.

12. The Global Coalition on Women and AIDS (2006a) Report on the Global AIDS Epidemic. New York, United Nations.

13. Pettifor AE, Rees HV, Steffenson A, Hlongwa-Madikizela L, MacPhail C, et al. (2004) HIV and Sexual Behaviour Among Young South Africans: A National Survey of 15-24 year olds. Reproductive Health Research Unit, University of Witwatersrand, Johannesburg.

14. Ajzen I, Fishbein M (1980) Understanding attitudes and predicting social behaviour. Prentice-Hall, New Jersey.

15. Ajzen I (2011) The theory of planned behaviour: reactions and reflections. Psychol Health 26: 1113-1127.

16. Rogers RW (1983) Cognitive and physiological processes in fear appeals and attitude change: A revised theory of protection motivation. In: Social psychology: A Sourcebook. JR Caccioppo, RE Petty (Eds.), New York: Guilford.

17. Rosenstock IM, Strecher VJ, Becker MH (1988) Social learning theory and the Health Belief Model. Health Educ Q 15: 175-183.

18. Hendershot CS, Stoner SA, George WH, Norris J (2007) Alcohol use, expectancies, and sexual sensation seeking as correlates of HIV risk behavior in heterosexual young adults. Psychol Addict Behav 21: 365-372.

19. DiClemente RJ, Crosby RA, Wingood GM, Lang DL, Salazar LF, et al. (2005) Reducing risk exposures to zero and not having multiple partners: Findings that inform evidence-based practices designed to prevent STD acquisition. Int J STD AIDS 16: 816-818.

20. Momodu A, Momodu MO (1998) School based AIDS education programme. Studies in Education 4: 18-21.

21. Bandura A (1994) Self efficacy. In: Encyclopaedia of human behaviour. V.S. Ramachaudran (Edr.), Academic press, New York.

22. Catania JA, Kegeles SM, Coates TJ (1990) Towards an understanding of risk behavior: an AIDS risk reduction model (ARRM). Health Educ Q 17: 53-72.

23. Akinyemi Z, Ankomah A, Ladipo O, Anyanti J (2002) Perceived faithbased invulnerability to HIV infection among female sex workers in Nigeria. XIVth International AIDS Conference. International AIDS society, Barcelona, Spain.

24. The Global Coalition on Women and AIDS (2006b) Educate Girls, fight AIDS. New York, United Nations.

25. Crawford M, Strebel A, Simbayi LC, Dwadwa-Henda N, Cloete A, et al. (2008) Gender, Power and Resistance to change among two communities in the Western Cape, South Africa. Feminism and Psychology 18: 157-182.

26. Mwamwenda TS (2014) African University adolescents gender differences in HIV/AIDs Vulnerability. Journal of AIDS and HIV research 6: 39-43.

27. Durojaiye O (2011) Knowledge, attitude and practice of HICV/AIDS: Behaviour change among tertiary education students in Lagos, Nigeria. Annals of Tropical Medicine and Public Health 41: 18-24.

28. Albarracin J, Plambeck CR (2010) Demographic factors and sexist beliefs as predictors of condom use among Latinos in the USA. AIDS Care 22: 1021-1028.

29. Barden-O'Fallon JL, deGraft-Johnson J, Bisika T, Sulzbach S, Benson A, et al. (2004) Factors associated with HIV/AIDS knowledge and risk perception in rural Malawi. AIDS Behav 8: 131-140.

30. Shobo Y (2007) Youth's perceptions of HIV infection risk: A sex-specific test of two risk models. African Journal of AIDS Research 6: 1-8. 
Citation: Taiwo AO (2015) The Role of Gender and Psychosocial Factors on Perceived Vulnerability to HIV/AIDS Infection among Young and Middle Aged Adults in Benin City, Nigeria. J Psychol Psychother 5: 175. doi:10.4172/2161-0487.1000175

Page 8 of 8

31. Macintyre K, Rutenberg N, Brown L, Karim A (2004) Understanding perceptions of HIV risk among adolescents in KwaZulu-Natal. AIDS Behav 8: 237-250

32. Zakrisson I, Anderzén M, Lenell F, Sandelin H (2012) Ambivalent sexism: a tool for understanding and improving gender relations in organizations. Scand J Psychol 53: 64-70.

33. Glick P, Fiske ST (1996) The Ambivalent Sexism Inventory: Differentiating hostile and benevolent sexism. Journal of Personality and Social Psychology 70: 491-512.

34. Liguori AL, Lamas M (2003) Gender, sexual citizenship and HIV/AIDS. Culture, Health \& Sexuality 5: 87.

35. Glick P, Fiske ST (2001) An ambivalent alliance. Hostile and benevolent sexism as complementary justifications for gender inequality. Am Psychol 56: 109-118.

36. Sakalli-UÄŸurlu N, Glick P (2003) Ambivalent sexism and attitudes toward women who engage in premarital sex in Turkey. J Sex Res 40: 296-302.

37. Swim JK, Hyers LL (2008) Sexism. In: Handbook of prejudice, stereotyping and discrimination. TD Nelson (Edr.), Psychology Press, Philadelphia, PA.

38. Begany JJ, Milbum MA (2002) Psychological predictors of sexual harassment: Authoritarianism, hostile sexism, and rape myths. Psychology of Men and Masculinity 3: 119-126.

39. Franzoi SL (2001) Is female body esteem shaped by benevolent sexism? Sex Roles 44: 177-188.

40. Goodwin SA, Fiske ST (2001) Power and gender. The double-edged sword of ambivalence. In: Handbook of the Psychology of Women and Gender. RK Unger (Edr.), Wiley, New York.

41. Masser B, Abrams D (1999) Contemporary sexism: The relationships among hostility, benevolence, and neo-sexism. Psychology of Women Quarterly 233: 503-517.

42. Wiener RL, Hurt L, Russell B, Mannen K, Gasper C (1997) Perceptions of sexual harassment: the effects of gender, legal standard, and ambivalent sexism. Law Hum Behav 21: 71-93.

43. Onuoha FN, Munakata T (2005) Correlates of adolescent assertiveness with HIV avoidance in a four-nation sample. Adolescence 40: 525-532.

44. Wallston KA (1996) Perceived control and health behaviour. In: Cambridge Handbook of Psychology, Health and Medicine. A Baum, C McManus, S Newman, J Weinman, R West (Eds.), Cambridge University Press, Cambridge, England.

45. Rickert VI, Sanghvi R, Wiemann CM (2002) Is lack of sexual assertiveness among adolescent and young adult women a cause for concern? Perspect Sex Reprod Health 34: 178-183.
46. Buhagiar K, Parsonage L, Osborn DPJ (2011) Physical health behaviours and health locus of control in people with schizophrenic-spectrum disorder and bipolar disorder: a cross-sectional comparative study with people with non-psychotic mental illness. BMC Psychiatry 11: 104.

47. St Lawrence JS (1993) African-American adolescents? knowledge, healthrelated attitudes, sexual behaviour and contraceptive decisions: implications for the prevention of adolescent HIV infection. J Consult Clin Psychol 61: 104-112.

48. Crisp BR, Barber JG (1995) The effect of Locus of control on the association between risk perception and sexual risk taking. Personality and individual Differences 19: 841-845.

49. Wallston BS, Wallston KA, Kaplan GD, Maides SA (1976) Development and validation of the health locus of control (HLC) scale. J Consult Clin Psychol 44: 580-585.

50. Wallston KA (2005) The validity of the multidimensional health locus of control scales. J Health Psychol 10: 623-631.

51. Beauclair R, Hens N, Delva W (2015) Concurrent partnerships in Cape Town, South Africa: race and sex differences in prevalence and duration of overlap. J Int AIDS Soc 18: 19372.

52. Janz NK, Becker MH (1984) The Health Belief Model: a decade later. Health Educ Q 11: 1-47.

53. Burns MJ (2005) AIDS, Health Locus of Control, Self-efficacy for safer sex practices and future time orientation as predictors of condom use in African American college students. Journal of Black Psychology 31: 172-188.

54. Sarker M, Milkowski A, Slanger T, Gondos A, Sanou A, et al. (2005) The role of HIV-related knowledge and ethnicity in determining HIV risk perception and willingness to undergo HIV testing among rural women in Burkina Faso. AIDS Behav 9: 243-249.

55. Isiugo-abanihe UC (1994) The socio-cultural context of high fertility among Igbo women. Int Sociol 9: 237-258.

56. Glick P, Fiske ST, Mladinic A, Saiz JL, Abrams D, et al. (2000) Beyond prejudice as simple antipathy: hostile and benevolent sexism across cultures. J Pers Soc Psychol 79: 763-775.

57. Counselling Centre, State University of New York at Buffalo (2001) Sexual Assertiveness Questionnaire.

58. Federal Ministry of Health (2006) 2005 National Sero-Prevalence Sentinel Survey. Federal Ministry of Health, Abuja, Nigeria.

59. Isiugo-Abanihe UC1 (2006) Sociocultural aspects of HIV/AIDS infection in Nigeria. Afr J Med Med Sci 35 Suppl: 45-55.

60. Gupta GR (2000) The best of times and the worst of times: implications of scientific advances in HIV prevention for women in the developing world. Ann N Y Acad Sci 918: 16-21. 